\title{
ATTITUDE ROLE IN CONDUCTING NON- PHARMACOLOGICAL TREATMENTS APPLIED TO DEMENTIA IN A QUALITY CONCEPT
}

\author{
Filippo Bergamo ${ }^{1}$ \\ 1 Istituzioni di Ricovero e di Educazione Venezia
}

\begin{abstract}
This text highlights the importance of the attitude of those who conduct nonpharmacological interventions applied to dementia. Analyze the concept of attitude how it fits into an equation that summarizes the idea of quality of the interventions themselves. The knowledge of the aspects to be taken into consideration when talking about attitude, excesses, references of other works highlight the importance of the "attitude" variable compared to the idea of a qualitative approach aimed at people with dementia subject to such non-pharmacological interventions. The text compares the previous reference to the concept of attitude and quality treated by Kitwood where its definition is described by a "vision" relative to the person with dementia with respect to an approach that defines its characteristics and actively includes it in a process quality. The proposed thesis stems from the observation and experience of 10 years of observation and proposition of validated nonpharmacological interventions applied to dementias, where the proposed attitude was found to be a very important variable compared to the answers relating to the proposed activation inputs.
\end{abstract}

ATTITUDE IN NON PHARMACOLOGICAL TREAT MENTS APPLIED TO DEMENTIA

Whenever you are preparing to carry out activities with people, whether or not they have a cognitive deficit, you choose in a more or less conscious way the type of attitude that you consider useful in order to get the most out of the proposed activities. What do we mean by attitude? What meanings do we give to our way of dealing with others and especially in this case with people with cognitive impairment? We start with two definitions of attitude:

- Way of disposing or presenting oneself, as a reflection of a certain mood or as a deliberately assumed form of behavior. 
- Willingness of each person to produce emotional, sentimental, behavior, determined by the family, social or work environment, regarding situations, groups or objects.

In both definitions, the will and determination of verbal and non-verbal behaviors are emphasized with the aim of producing, through particular stimuli, responses to these. If you desire to have is a certain type of communication with the people we approach and it is important and necessary that there is adherence and relevance between verbal and non-verbal communication.

Although this type of informations proposed are widely known, it is not so obvious in practice and in many case it leads to some excesses and there are frequent whenever you hear about activities with people with cognitive impairment.

We have tried to divide them into three typologies relating to management:

Excessively Clinical: extremely technical attitude, fully observant of the setting, techniques and strategies. Rather cold and detached in the relationship in order to pollute the outcome of the required performances as little as possible.

Excessively Sweetly: attitude not very inclined to technical or setting aspects, the goal is to make the person feel good at any cost therefore willing to any means in order to obtain a positive feedback.

Excessively Eclectic: an attitude that swings extremely technical behaviors at moments of absolute affectivity, sometimes losing sight of one or the other thing.

What is the most correct attitude to take during an activity? Is it possible to give dignity to the person with whom one is relating?

The latter question is always one of the most difficult for those involved in cognitive activation activities. In addition to the objectives that are pursued, in order to have the best possible setting and therefore less pressing from performance needs, we try to propose contexts with playful characteristics, sometimes even playing, and therefore easily perceived as trivial, of little value or even childish.

It therefore becomes essential to have the utmost attention to every rationalizable element you decide to use during the activities ( $T$ ab 1).

\begin{tabular}{l} 
Tab.1 \\
Elements: \\
\hline Objectives \\
Technical knowledge \\
Strategies \\
Times \\
Communicative choices \\
Relational choices \\
Our emotions \\
Environments \\
...
\end{tabular}

Figure 
There are several things to keep in government but another essential element must be added: "love".

We searched for a definition of love that could make us understand better what we are talking about when we refer to this term and chose this:

Love: feeling of affection for a person, which manifests itself as a desire to procure his or her good and to seek companionship. When does love become a rationalizable element? When it is aware and therefore usable during the proposed activity. Often the loving attitude is manifested through expressions of compliance, reproach, recommendation, authoritativeness, seduction or other ... in order to obtain the best possible response to the proposed stimulus.

Everyone is the animator of their activities, each for their own roles.

With this approach we try to offer ourselves convinced that a good strategy and a good attitude can give a good cog nitive activation respectful of the person and his dignity Technique and sentiment must therefore be sides of the same coin and we must continuously and consciously used it in order to propose an intervention that respects all the useful components to make the activity useful, free, pleasant and dignified.

\section{ATTITUDE IN LITERATURE: KITWOOD END THE PERSONHOOD}

The concept of personhood was first applied to people with dementia by Kitwood. The concept can be complex to define, but it is used generally to describe what makes up the attributes of being a person.

According to Kitwood personhood is a standing or status that is bestowed upon one human being, by others, it implies recognition, respect and trust'. Through this recognition, respect and trust, the personhood of an individual will be enhanced as well as their wellbeing. If the opposite occurs, then personhood will diminish, leading to "illbeing".It is erroneous to suggest that people with dementia should be in a constant state of wellbeing because this is not a maintainable state for any person, well or unwell (Jones and Mitchell 2014).

Despite this recognition, Kitwood asserted that people with dementia, who mostly experienced illbeing, were more likely to be exhibiting feelings of undermined personhood. Those people with dementia who experienced more frequent illbeing were often living in care environments that were not supportive of the concept of personhood. Healthcare professionals in these care environments were not purposely undermining the personhood of the people they were caring for, but were unaware of the specialist 
needs required by these individuals. Kitwood's theory sought to identify behaviours that would undermine a person's wellbeing - malignant social psychology - and behaviours that would enhance a person's wellbeing - positive person work - to enable healthcare professionals to deliver optimum levels of person-centred care that would retain and enhance personhood for people with dementia.

The theories of malignant social psychology and positive person work assist healthcare professionals in implementing person-centred practices. However, the essential psychological needs of people with dementia should also be considered and include: Comfort: the feeling of trust that comes from others.

Attachment: security and finding familiarity in unusual places.

Inclusion: being involved in the lives of others.

Occupation: being involved in the processes of normal life.

Identity: what distinguishes a person from others and makes them unique. Kitwood theorised that these psychological needs are present in all human beings, but are likely to be heightened for people with dementia because they are usually more vulnerable and less likely to be able to take action to satisfy these needs. Essentially, these five psychological needs contribute to the expression of love.

Retaining and enhancing personhood is important for people with dementia because of the anticipated decline in their cognitive functioning. For people with advanced dementia, it is likely that the nurse or other health and social care professionals will be responsible for meeting these psychological needs, especially given the large number of people with dementia in long-term care facilities.

The care staff and care environment determine whether the psychological needs of people with dementia are met and if personhood is maintained or enhanced subsequently. This depends larg ely on whether care staff behaviour corresponds more with malignant social psychology or positive person work. 


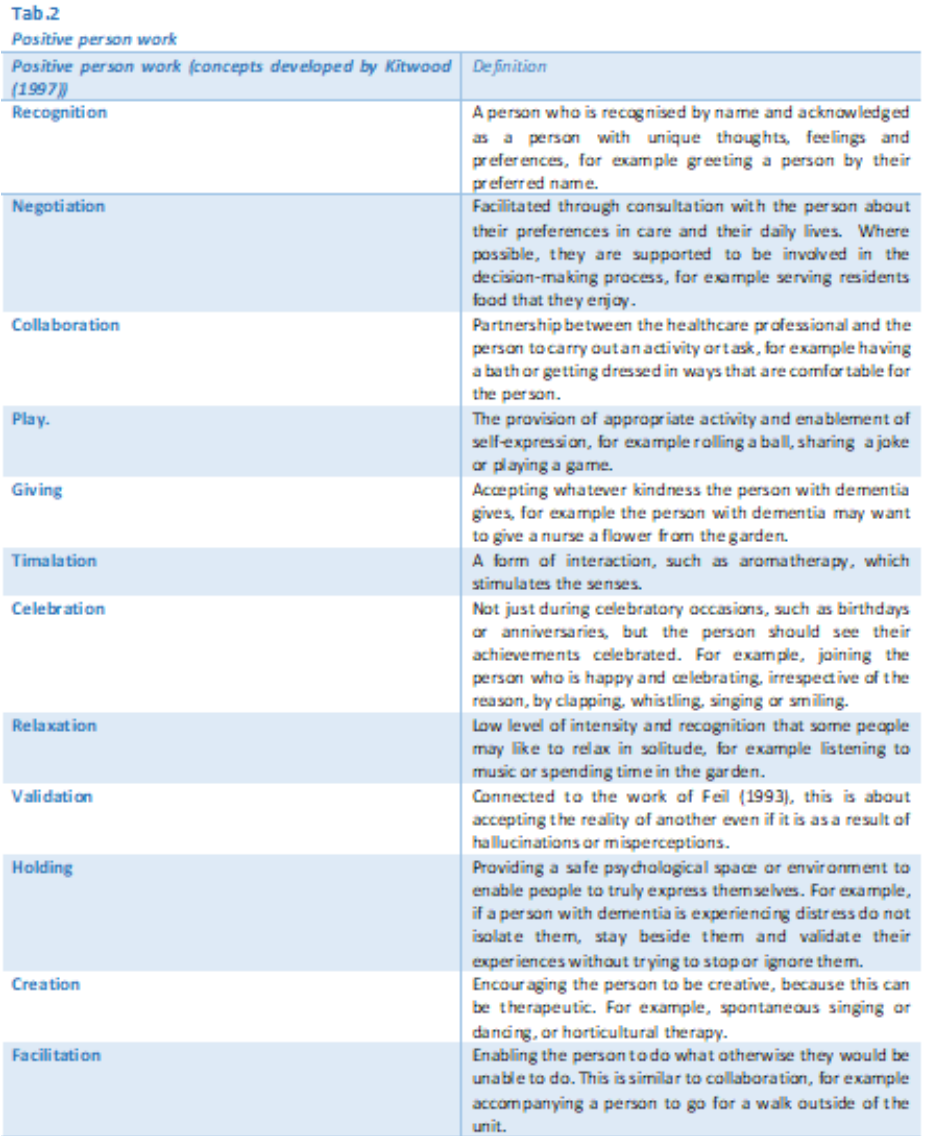

Figure

QUALIY IN NON PHARMACOLOGICAL TRET MENTS APPLIED TO DEMNTIA

Non-pharmacological treatments (tab. 3) therefore represent a series of interventions that use specific strategies to cognitively activate the people to whom they are proposed according to specific objectives aimed at the brain areas to be activated.

Tab. 3

Non-pharmacological therapies:

Standard therapies:

Behavioural the rapy

Reality orientation

Validation the rapy

Rem iniscence therapy

Alternative therapies:

Art the rapy

Music therapy

Activity the rapy

Complementary the rapy:

Aromatherapy

Bright-light therapy

Mult isensory approaches

Brief psychotherapies

Cognitive-behavioural the rapy

Interpersonal therapy 
Figure

As anticipated, however, the technique is not enough, but the variables that come into play are represented by the number of operators involved, the set of technical knowledge also relating to the various forms of dementia, the time taken, the setting, the attitude and the worthy of the person.

$$
Q-\left(\frac{(\mathbf{W}+\mathbf{K}+\mathbf{A}) \times \mathbf{T}}{\mathbf{P}^{\mathrm{Ds}}}\right)^{s}
$$

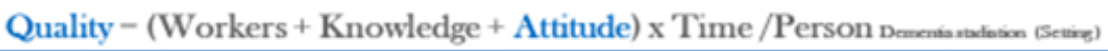

Figure

We have therefore tried to translate all of this into a formula that gives the sense of what it means to translate a non-pharmacological intervention into quality as a product of a series of elements in relation to the person and personality, as well as to the pathology and level of the same. The setting becomes of exponential importance as attention to the environment and its structuring including the actors present with their experience, knowledge and attitude.

Unlike what has been reported in other scientific papers, what we want to introduce as a new concept among the variables to be taken into consideration in non-pharmacological treatments applied to dementia is probably "Attitude". The other elements in this formula are only related to each other. When working with people, all the formulas that try to frame an operating method seem to never be sufficient to explain the correct modus operandi, which is why they need to be enriched in a logic of personalization of care.

Referencies:

Ballard, C. G., O'Brien, J., James, I., et al (2001) Dementia: Management of Behavioural and Psychological Symptoms. Oxford: Oxford University Press.

Bird, M., Llewellyn-Jones, R., Smithers, H., et al (2002) Psychosocial Approaches to Challenging Behaviour in Dementia: A Controlled Trial. Report to the Commonwealth Department of Health and Ageing. Canberra: CDHA.

Burgio, L. \& Fisher, S. (2000) Application of psychosocial interventions for treating behavioural and psychological symptoms of dementia. International Psychogeriatrics, 12, 
(suppl. 1), 351-358.

Emerson, E. (1998) Working with people with challenging behaviour. In Clinical Psychology and People with Intellectual Disabilities (eds E. Emerson, C. Hatton, J. Bromley, et al), pp. 127-153. Chichester: John Wiley \& Sons.

Emerson, E., Thompson, S., Reeves, D., et al (1995) Descriptive analysis of multiple response topographies of challenging behaviour across two settings. Research in Developmental Disabilities, 16, 301-329

Kitwood T (1993) T owards a theory of dementia care: the interpersonal process. Ageing and Society. 13, 1, 51-67.

Kitwood T (1995) Positive long-term changes in dementia: some preliminary observations. Journal of Mental Health. 4, 2, 133-144.Woods, R. T. (1999) Psychological Problems of Ageing. Chichester: John Wiley and Sons.

Kitwood, T. (1997) Dementia Reconsidered: The Person Comes First. Bucking ham: Open University Press.

La Vigna, G. \& Donnellan, A. (1986) Alternative to Punishment: Solving Behaviour Problems with Non-aversive Strategies. New York: Irvington.

Marriott, A., Donaldson, C., Tarrier, N., et al (2000) Effectiveness of cognitive-behavioural family intervention in reducing the burden of care in carers of patients with Alzheimer's disease. British Journal of Psychiatry, 176, 557- 562.

National Institute for Health and Clinical Excellence (NICE). Dementia: A NICE-SCIE Guideline on supporting people with dementia and their careers in health and social care. National Clinical Practice Guideline Number 42. Vol: The British Psychological Society and Gaskell; 2007.

Rogers C (1961) On Becoming a Person. A Therapist's View of Psychotherapy. Houghton Mifflin, Boston MA.

Spector, A., Orrell, M., Davies, S., et al (2001) Can reality orientation be rehabilitated? Development and piloting of an evidence-based programme of cognition-based therapies for people with dementia. Neuropsychological Rehabilitation, 11, 377-397. Spector, A., Orrell, M., Davies, S., et al (2002a) Reality orientation for dementia. Cochrane Library, issue 3. Oxford: Update Software.

Spector, A., Orrell, M., Davies, S., et al (2002b) Reminiscence therapy for dementia. Cochrane Library, issue 3. Oxford: Update Software. 